\title{
PENGARUH PEMBERIAN PUPUK KANDANG AYAM DAN STRESS AIR TERHADAP PERTUMBUHAN BIBIT KELAPA SAWIT (ELAEIS GUINEENSIS JACQ.) VARIETAS TENERA DI PRE-NURSERY
}

\author{
Oleh: \\ Culina Siringo-ringo ${ }^{1)}$ \\ Agnes Imelda Manurung ${ }^{2)}$ \\ Bilter A. Sirait ${ }^{3)}$ \\ Universitas Darma Agung, Medan ${ }^{1,2,3)}$ \\ E-mail: \\ culinaringo97@gmail.com $^{1)}$ \\ $\frac{\text { manurungagnesimelda@gmail.com }^{2)}}{\text { dapejel.rait@yahoo.com }}{ }^{3)}$
}

\section{ABSTRACT}

This study aims at analyzing the effect of chicken manures and water stress on the growth of oil palm (Elaeis guineensis Jacq.) seedlings of tenera varieties in prenursery. The study was carried out at Jln. Bunga Ncole Raya XXX No.4, Victory Tani Village, Medan Tuntungan District with an altitude of \pm 12 meters above sea level, starting from May to August 2020. The research method used a factorial randomized block design (RAK) consisting of two factor, the first factor is the treatment dose of chicken manures consisting of 3 levels: $A O=$ control, $A 1=25 \%$ chicken manure and $A 2=50 \%$ chicken manure. The second factor is the provision of water stress consisting of 3 levels: $R 1=0.3 \mathrm{l} /$ polybag/day, $R 2=0.3 \mathrm{l} /$ polybag/2day, and $R 3=0.3$ l/polybag/4day. The results showed that the dose of chicken manures had a significant effect on plant height, leaf length, leaf width and wet weight of oil palm seedlings. Water stress treatment significantly affected plant height, leaf length, leaf width of oil palm seedlings. The combination of treatment between the application of chicken manures and water stress is not significant for all observed variables.

Keywords: chicken manures, water stress and oil palm seeds

ABSTRAK
Penelitian ini bertujuan untuk menganalisa pengaruh pemberian pupuk kandang ayam
dan stress air terhadap pertumbuhan bibit kelapa sawit (Elaeis guineensis Jacq.) varietas
tenera di pre-nursery. Penelitian dilaksanakan di Jln.Bunga Ncole Raya XXX No.4,
Kelurahan Kemenangan Tani, Kecamatan Medan Tuntungan dengan ketinggian tempat
\pm 12 mdpl, yang dimulai pada bulan Mei hingga bulan Agustus 2020. Metode Penelitian
menggunakan Rancangan Acak Kelompok (RAK) faktorial terdiri dari dua factor,
faktor pertama adalah perlakuan dosis pupuk kandang ayam terdiri atas 3 taraf: A0 =
kontrol, A1= 25\% Pupuk kandang ayam dan A2 = 50\% pupuk kandang ayam. Faktor
kedua adalah pemberian stress air terdiri atas 3 taraf: R1 = $0.31 /$ polybag/hari, R2 = 0.3
1/polybag/2hari, dan R3 = 0.3 1/polybag/4hari. Hasil penelitian menunjukkan bahwa,
perlakuan dosis pupuk kandang ayam berpengaruh nyata terhadap tinggi tanaman,
panjang daun, lebar daun dan bobot basah tanaman bibit kelapa sawit. Perlakuan
pemberian stress air berpengaruh nyata terhadap tinggi tanaman, panjang daun, lebar 
daun bibit kelapa sawit. Kombinasi perlakuan antara pemberian pupuk kandang ayam dan stress air tidak nyata terhadap seluruh peubah amatan.

Kata kunci : pupuk kandang ayam, stress air dan bibit kelapa sawit

\section{PENDAHULUAN}

Tanaman kelapa sawit (Elaeis guineensis Jacq.) sangat banyak manfaatnya seperti bahan bakar alternatif biodisel, bahan kompos, bahan dasar lainnya seperti industri farmasi, industri pangan, dan industri kosmetika. Prospek kebutuhan pasar untuk produk hilir olahan kelapa sawit cukup besar, karena permintaan mengalami peningkatan yang cukup besar setiap tahun, tidak hanya di dalam negeri, tetapi juga di luar negeri. Faktor yang sangat penting untuk menjamin keberhasilan pembibitan salah satunya adalah kemampuan menyediakan air untuk bibit dalam jumlah yang cukup dengan jaringan irigasi yang baik (Sulistyo, 2010).

Kandungan N, P, dan K pada pupuk kandang dari kotoran ayam berkisar $1,5-1,7 \% \mathrm{~N}, 1,9 \% \mathrm{P}$ dan 1,5\% K. Kandungan ini bisa berbeda-beda tergantung jenis pakan ayam. Kandungan zat hara pupuk kotoran ayam lebih tinggi dari kandungan hara pukan sapi ataupun kuda. Adapun tujuan Penelitian adalah untuk mampu menjelaskan pengaruh pemberian pupuk kandang ayam dan stress air terhadap pertumbuhan bibit kelapa sawit (Elaeis guieneensis Jacq.) varietas tenera pada pembibitan awal (pre-nursery).

\section{METODE PELAKSANAAN}

Lokasi dan Waktu Penelitian.

Penelitian ini dilaksanakan di Jln Bunga Ncole raya XXX no.4, Kelurahan, Kemenangan tani, Kecamatan Medan Tuntungan pada ketinggian $12 \mathrm{mdpl}$. Penelitian dilakukan pada bulan Mei hingga Agustus 2020.

\section{Bahan dan Alat Penelitian.}

Bahan yang digunakan adalah kecambah kelapa sawit Tenera (Dura $\mathrm{x}$ Pisifera) Varietas Simalungun Indonesia Oil Palm Research Instute (IOPRI) dari Pusat Penelitian Kelapa Sawit (PPKS/RISPA) Jln. Brigjen Katamso No.51 Kampung Baru Medan. Selain itu, dibutuhkan polybag pupuk kandang ayam, air. Alat-alat yang digunakan pada penelitian ini seperti cangkul, gembor, penggaris, handsprayer, kertas label sampel, tali plastik, ember, buku tulis, kalkulator, jangka sorong, label perlakuan, triplek, spidol,pensil, plastik UV serta alat lainnya yang mendukung penelitian.

\section{Metode Penelitian}

Metode penelitian menggunakan Rancangan Acak Kelompok (RAK) faktorial, terdiri dari 2 faktor, yaitu faktor pupuk kandang ayam (A) yang terdiri dari 3 taraf $\mathrm{A}_{0}=0 \%$ Pupuk kandang ayam (0 g/polybag), $\mathrm{A}_{1}=25 \%$ Pupuk kandang ayam (250 g/polybag), $\mathrm{A}_{2}=50 \%$ pupuk kandang ayam (500 
g/polybag). Faktor dosis pemberian stress air $(\mathrm{R})$ terdiri dari 3 taraf , $\mathrm{R}_{1}=0,3$ liter/polybag/hari, $\quad \mathrm{R}_{2}=\quad 0,3$ liter/polybag/2hari, $\quad \mathrm{R}_{3}=0,3$ liter/polybag/4hari

\section{HASIL DAN PEMBAHASAN}

Tinggi Tanaman ( $\mathrm{cm}$ )

Grafik pertumbuhan tinggi tanaman bibit kelapa sawit umur 4-12 MST pada berbagai dosis pupuk kandang ayam disajikan pada Gambar 1.

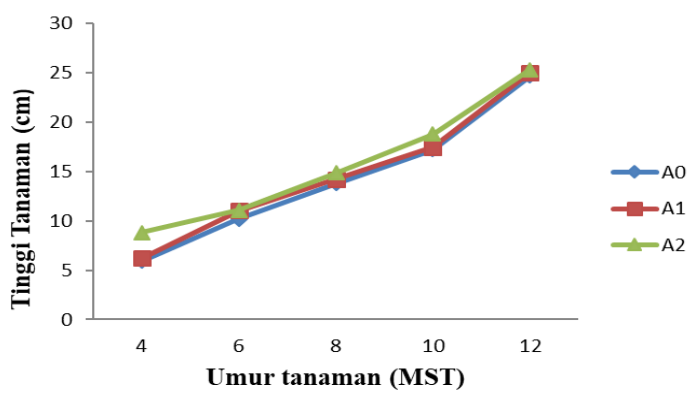

Gambar 1. Grafik Pertumbuhan Tinggi Tanaman Bibit Kelapa Sawit Umur 4-12 MST Pada Berbagai Dosis P upuk Kandang Ayam.

Gambar 1 memperlihatkan peningkatan pertumbuhan tinggi tanaman bibit kelapa sawit lebih tinggi pada pemberian perlakuan A2 dibanding pada perlakuan A0 dan A1.

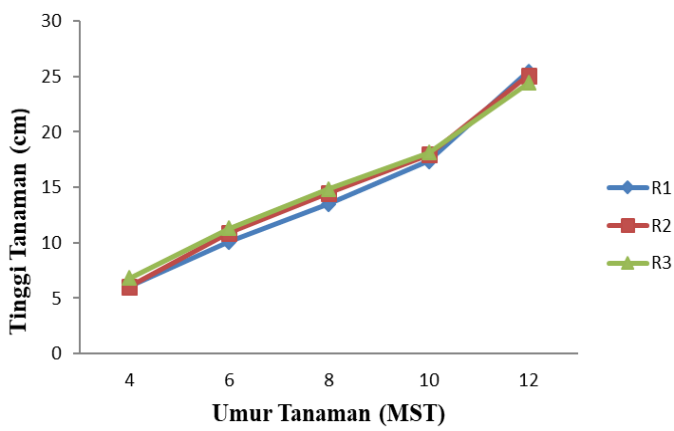

Gambar 2. Grafik Pertumbuhan Tinggi Tanaman Bibit Kelapa Sawit Pada Umur 4-12 MST Akibat Perlakuan Pemberian Air

Dari Gambar 2 memperlihatkan bahwa pertambahan tinggi tanaman bibit kelapa sawit lebih cepat pada perlakuan R1, diikuti oleh R2 dan R3.

Rataan tinggi tanaman bibit kelapa sawit pada umur 4, 6, 8, 10, dan 12 MST akibat pemberian dosis pupuk kandang ayam dan stress air ditampilkan pada Tabel 1.

Tabel 1. Rataan Tinggi Bibit Tanaman Kelapa Sawit Akibat Pemberian Pupuk Kandang Ayam Dan Stress Air Pada Umur 4,6,8,10, Dan 12 Minggu Setelah Tanam $(\mathrm{cm})$

\begin{tabular}{cccccc}
\hline Perlakuan & \multicolumn{5}{c}{ Tinggi Tanaman $(\mathrm{cm})$} \\
\cline { 2 - 6 } & $4 \mathrm{MST}$ & $6 \mathrm{MST}$ & $8 \mathrm{MST}$ & $10 \mathrm{MST}$ & $12 \mathrm{MST}$ \\
A0 & 5.91 & 10.17 & 13.76 & 17.86 & $23.96 \mathrm{c}$ \\
A1 & 6.23 & 11.01 & 14.36 & 17.38 & $25.05 \mathrm{~b}$ \\
A2 & 6.83 & 11.07 & 14.72 & 18.65 & $25.32 \mathrm{a}$ \\
R1 & 6.81 & 11.30 & 14.86 & 18.47 & $25.44 \mathrm{a}$ \\
R2 & 6.10 & 10.88 & 14.49 & 18.12 & $25.10 \mathrm{~b}$ \\
R3 & 6.06 & 10.11 & 13.49 & 17.31 & $24.44 \mathrm{c}$ \\
\hline
\end{tabular}

Keterangan : Angka yang diikuti oleh huruf yang sama dalam kolom yang sama berarti tidak berbeda dengan uji Duncan pada taraf 5\% 
Pada perlakuan dosis pupuk kandang ayam, tinggi tanaman yang tertinggi terdapat pada perlakuan A2 berbeda nyata dengan A1 dan A0. Perlakuan pemberian air tanaman tertinggi terdapat pada taraf $\mathrm{R} 1$ berbeda nyata dengan R2 dan R3.pupuk kandang ayam juga dapat memberikan unsur nitrogen yang tepat untuk pertumbuhan bibit kelapa sawit. Pupuk kandang ayam mengandung unsur hara $\mathrm{N}, \mathrm{P}, \mathrm{K}$ dan unsur hara lainnya yang cukup untuk pertumbuhan tanaman, terutama unsur hara $\mathrm{N}$ berfungsi sebagai pembelahan sel. Pupuk kandang ayam yang merupakan pupuk organic berfungsi untuk mensubstitusi perbaikan struktur tanah, sumber nutrisi bagi perkembangan morfologis tanaman. Kandungan nutrisi pupuk kandang lebih tinggi jika dibandingkan dengan jenis pupuk kandang lainnya. Dekomposisi pupuk kandang ayam akan menyatu di dalam tanah. Proses pelapukan bahan mineral. Bahan organik juga dapat dijadikan sebagai bahan makanan mikroba dala tanah. Pupuk kandang dapat berfungsi sebagai merangsang pertumbuhan keseluruh bagian batang dan daun tanaman. Kandungan Nitrogen yang tinggi pada pupuk kandang ayam akan mendorong laju pertumbuhan tanaman, dan unsur hara $\mathrm{N}$ merupakan unsur hara makro yang dibutuhkan dalam pembentukan bagian- bagian vegetatif tanaman seperti, daun, batang, dan akar

Hubungan antara dosis pupuk kandang ayam terhadap tinggi tanaman bibit kelapa sawit pada umur 12 MST diperlihatkan pada Gambar 3.

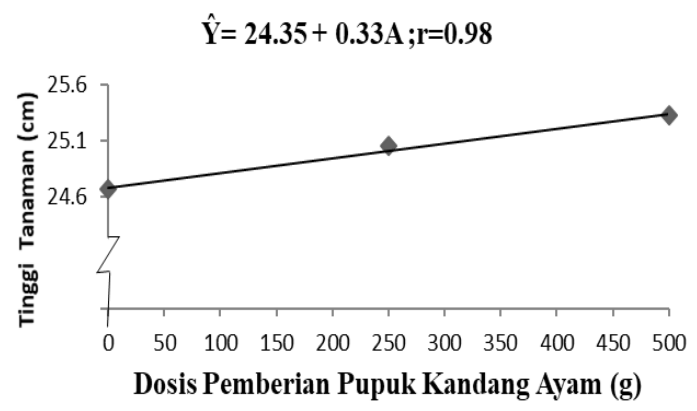

Gambar 3.Kurva respon pengaruh dosis pupuk kandang ayam terhadap tinggi tanaman bibit kelapa sawit pada umur 12 MST.

Gambar 3 menunjukkan bahwa semakin tinggi pemberian jumlah pukan ayam, tinggi tanaman bibit kelapa sawit semakin meningkat mengikuti kurva regresi linier, dengan persamaan $\hat{\mathrm{Y}}=$ $24.34+0.33 \mathrm{~A} ; \mathrm{r}=-0.98$ yang berarti peningkatan pemberian dosis pupuk kandang ayam $1 \mathrm{~g}$ akan menambah tinggi tanaman sebesar $0.33 \mathrm{~cm}$ dengan keeratan hubungan $98 \%$.

Hubungan antara frekuensi pemberian air dengan tinggi tanaman 
bibit kelapa sawit pada umur 12 MST diperlihatkan pada Gambar 4.

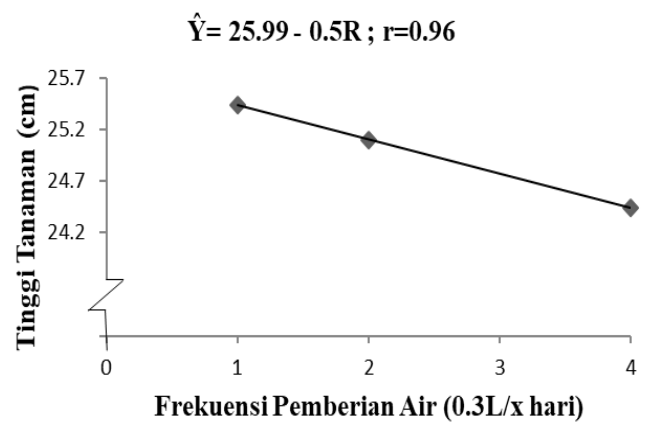

Gambar 4. Kurva respon pengaruh pemberian air terhadap tinggi tanaman bibit kelapa sawit pada umur 12 MST.

Gambar 4 memperlihatkan bahwa lama frekuensi pemberian air, maka tinggi tanaman bibit kelapa sawit semakin menurun, dengan persamaan regresi linear $\hat{\mathrm{Y}}=25.99-0.5 \mathrm{R} ; \mathrm{r}=0.96$ yang berarti semakin lama frekuensi pemberian air 0,3 liter/polybag/2 hari akan menurunkan tinggi tanaman sebesar $0.5 \mathrm{~cm}$ dengan keeratan hubungan 96\%. Hal ini disebabkan dengan pemberian air $1 \times 1$ hari dapat selalu menjamin ketersediaan air pada bibit tanaman kelapa sawit. Menurut Mubiyanto (2007) bahwa bertambahnya volume ukuran organ pada tanaman secara menyeluruh, ini merupakan reaksi dari bertambahnya jaringan dan ukuran sel. Menurut Ariyanti (2018) bahwa air sangat berperan dalam pengangkutan dan transportasi unsur hara dari akar ke jaringan tamaman, sebagai pelarut garam-garam, mineral serta sebagai penyusun jaringan tanaman lainnya. Hal ini berarti bahwa semakin tersediannya air maka unsur hara oleh akar tanaman menjadi lebih baik, sehingga akan meningkatkan pertumbuhan tanaman.

Hasil penelitian memperlihatkan bahwa tidak terdapat perbedaan yang cukup besar pertumbuhan bibit kelapa sawit dengan frekuensi pemberian air 1 x 1 hari, 1 x 2 hari dan 1 x 4 hari . Hal ini menujukkan bahwa kebutuhan air bagi tanaman masih tercukupi.

Air sangat penting bagi tanaman sebagai bahan baku proses fotosintesis. Air juga berfungsi sebagai pelarut, reagensia pada berbagai reaksi kimia dan sebagai pemelihara tekanan turgor tanaman. Selain dialokasikan untuk disimpan di dalam organ, sebagian hasil fotosintesis dirombak untuk menghasilkan senyawa-senyawa organik terlarut untuk menurunkan potensial osmotik sel (osmoregulasi) agar tanaman dapat beradaptasi pada kondisi kekeringan walaupun pertumbuhannya menjadi lambat (Maryani dan Gusmawartati, 2010).

\section{Panjang Daun (cm)}

Rataan panjang daun tanaman bibit kelapa sawit pada umur 12 MST akibat pengaruh perlakuan pemberian dosis pupuk kandang dan stress air disajikan pada Tabel 2. 
Tabel 2. Rataan Panjang Daun Bibit Tanaman Kelapa Sawit Akibat Pemberian Pupuk Kandang Ayam Dan Stress Air Pada Umur 12 Minggu Setelah Tanam (cm)

\begin{tabular}{cccccc}
\hline Perlakuan & R1 & R2 & R3 & Total & Rataan \\
\hline A0 & 18.58 & 20.93 & 19.57 & 59.08 & $19.69 \mathrm{c}$ \\
A1 & 21.25 & 18.48 & 19.73 & 60.47 & $20.16 \mathrm{~b}$ \\
A2 & 21.87 & 20.92 & 18.45 & 61.23 & $20.41 \mathrm{a}$ \\
\hline Total & 61.70 & 61.33 & 57.75 & 180.78 & \\
\hline Rataan & $20.57 \mathrm{a}$ & $20.44 \mathrm{~b}$ & $19.25 \mathrm{c}$ & &
\end{tabular}

Keterangan : Angka yang diikuti oleh huruf yang sama dalam kolom yang sama berarti tidak berbeda dengan uji Duncan pada taraf 5\%

Tabel 2 memperlihatkan bahwa perlakuan dosis pupuk kandang ayam pada umur 12 MST, panjang daun tanaman bibit kelapa sawit terpanjang pada perlakuan $\mathrm{A} 2$, berbeda nyata dengan A1 dan A0. Perlakuan frekuensi pemberian air, panjang daun tanaman bibit kelapa sawit terpanjang pada perlakuan $\mathrm{R} 1$, berbeda nyata dengan $\mathrm{R} 2$ dan R3.

Hubungan antara dosis pupuk kandang ayam dengan panjang daun bibit kelapa sawit pada umur 12 MST diperlihatkan pada Gambar 5.

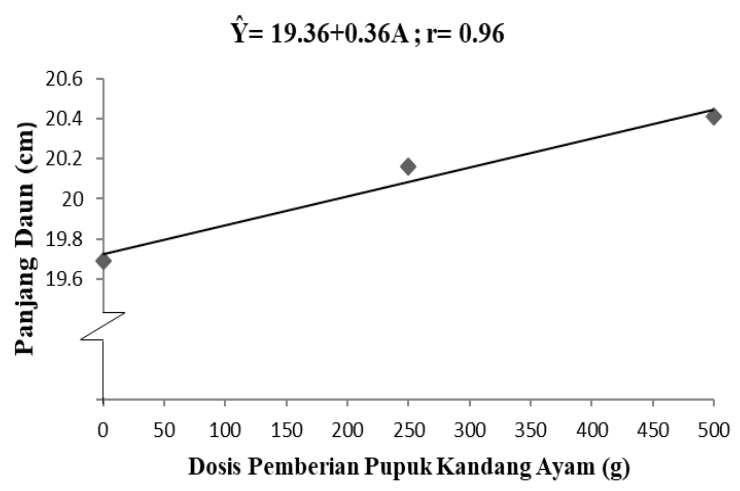

Gambar 5. Kurva Respon Pengaruh Dosis Pupuk Kandang Ayam Terhadap Panjang
Daun Bibit Kelapa Sawit Pada Umur 12 MST

Gambar 5 memperlihatkan bahwa semakin tinggi pemberian dosis pupuk kandang ayam, maka panjang daun bibit tanaman kelapa sawit semakin meningkat mengikuti kurva regresi linear dengan persamaan $\hat{Y}$ $=19.36+0.36 \mathrm{~A} ; \mathrm{r}=0.96$ yang berarti peningkatan pemberian dosis pupuk kandang ayam $1 \mathrm{~g}$ akan meningkatkan panjang daun sebesar $0.36 \mathrm{~cm}$ dengan keeratan hubungan $96 \%$.

Hubungan antara pemberian air dengan panjang daun tanaman bibit kelapa sawit pada umur 12 MST disajikan pada Gambar 6. 


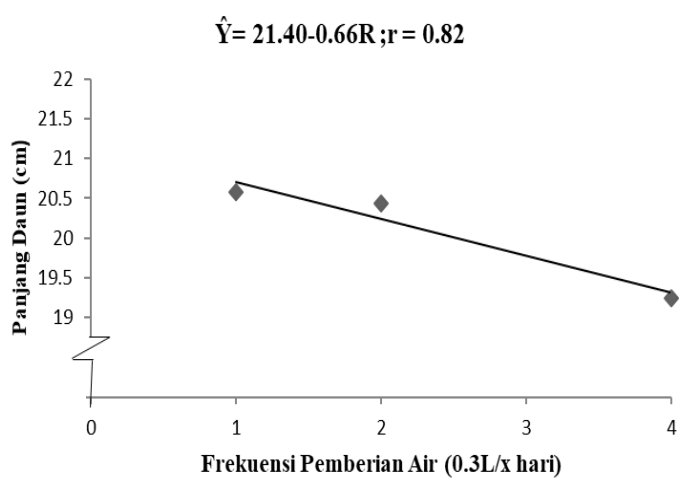

Gambar 6. Kurva Respon Pengaruh Pemberian Air Terhadap Panjang Daun Tanaman Bibit Kelapa Sawit Pada Umur 12 MST

Gambar 6 memperlihatkan bahwa semakin lama frekuensi pemberian air, maka panjang daun bibit kelapa sawit semakin menurun

Tabel 3. Rataan Lebar Daun Bibit Tanaman Kelapa Sawit Akibat Pemberian Pupuk Kandang Ayam Dan Stress Air Pada Umur 12 Minggu Setelah Tanam (cm)

\begin{tabular}{cccccc}
\hline Perlakuan & R1 & R2 & R3 & Total & Rataan \\
\hline A0 & 3.78 & 3.62 & 3.55 & 10.95 & $3.65 \mathrm{c}$ \\
A1 & 3.97 & 3.43 & 3.63 & 11.03 & $3.68 \mathrm{~b}$ \\
A2 & 4.02 & 4.05 & 3.55 & 11.62 & $3.87 \mathrm{a}$ \\
\hline Total & 11.77 & 11.10 & 32.20 & 33.60 & \\
\hline Rataan & $3.92 \mathrm{a}$ & $3.70 \mathrm{~b}$ & $3.58 \mathrm{c}$ & &
\end{tabular}

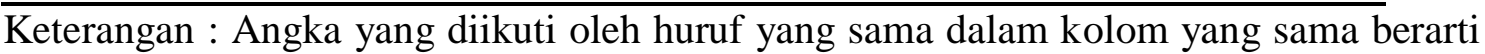
tidak berbeda dengan uji Duncan pada taraf 5\%

Tabel 3 memperlihatkan bahwa perlakuan dosis pupuk kandang ayam pada $12 \mathrm{MST}$, lebar daun tanaman bibit kelapa sawit terlebar terdapat pada perlakuan A2 berbeda nyata dengan A1 dan A0. Perlakuan frekuensi pemberian air, daun tanaman bibit kelapa sawit terlebar terdapat pada taraf perlakuan mengikuti kurva regresi linear dengan persamaan $\hat{\mathrm{Y}}=21.40-0.66 \mathrm{R} ; \mathrm{r}=$ 0.82 yang berarti semakin lama frekuensi pemberian air 0.3 liter/polybag/2 hari kelapa sawit sebesar $0.66 \mathrm{~cm}$ dengan keeratan hubungan $82 \%$.

\section{Lebar Daun (cm)}

Rataan lebar daun tanaman bibit kelapa sawit pada umur 12 MST akibat pengaruh perlakuan pemberian dosis pupuk kandang ayam dan stress air disajikan pada Tabel 3. akan menurunkan panjang daun bibit 


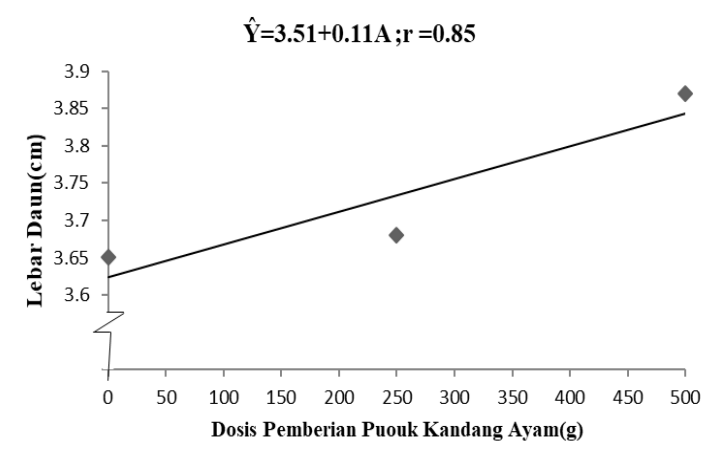

Gambar 7. Kurva Respon Pengaruh Pemberian Pupuk Kandang Ayam Terhadap Lebar Daun Bibit Kelapa Sawit Pada Umur 12 MST

Gambar 7 memperlihatkan bahwa semakin tinggi dosis pupuk kandang ayam, maka lebar daun bibit kelapa sawit akan semakin bertambah mengikuti kurva regresi linear dengan persamaan $\hat{\mathrm{Y}}=3.51+0.11 \mathrm{~A} ; \mathrm{r}=0.85$ yang berarti peningkatan pemberian dosis pupuk kandang ayam $1 \mathrm{~g}$ akan menurunkan lebar daun sebesar $0.11 \mathrm{~cm}$ dengan keeratan hubungan $85 \%$.

Hubungan antara pemberian frekuensi air dengan lebar daun tanaman bibit kelapa sawit pada umur 12 MST disajikan pada Gambar 8.

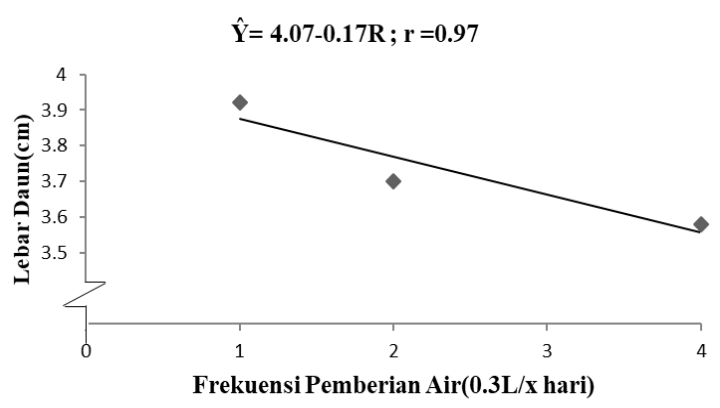

Gambar 8. Kurva Respon Pengaruh Pemberian Stress Air Terhadap Lebar Daun Tanaman Bibit Kelapa Sawit Pada Umur 12 MST

Gambar 8 memperlihatkan bahwa lama frekuensi pemberian air, maka lebar daun bibit kelapa sawit semakin menurun mengikuti kurva regresi linear dengan persamaan $\hat{Y}=$ $4.07-0.17 \mathrm{R} ; \mathrm{r}=0.97$ yang berarti semakin lama frekuensi pemberian air 0.3 liter/polybag/2 hari akan menurunkan lebar daun bibit kelapa sawit sebesar $0.17 \mathrm{~cm}$ dengan keeratan hubungan $97 \%$.

\section{Bobot Basah (g)}

Rataan bobot basah tanaman bibit kelapa sawit pada umur 12 MST akibat pengaruh pemberian dosis pupuk kandang ayam dan stress air disajikan pada Tabel 4.

Tabel 4. Rataan Bobot Basah Bibit Tanaman Kelapa Sawit Akibat Pemberian Pupuk Kandang Ayam Dan Stress Air Pada Umur 12 Minggu Setelah Tanam (g)

\begin{tabular}{cccccc}
\hline Perlakuam & R1 & R2 & R3 & Total & Rataan \\
\hline A0 & 8.00 & 7.33 & 6.33 & 21.67 & $7.22 \mathrm{c}$ \\
A1 & 8.00 & 8.33 & 7.67 & 24.67 & $8.22 \mathrm{~b}$ \\
\hline
\end{tabular}




\begin{tabular}{cccccc}
\hline $\mathrm{A} 2$ & 8.67 & 8.67 & 8.67 & 25.33 & $8.44 \mathrm{a}$ \\
\hline Total & 24.67 & 24.33 & 22.67 & 71.67 & \\
\hline Rataan & $8.22 \mathrm{a}$ & $8.11 \mathrm{~b}$ & $7.56 \mathrm{c}$ & &
\end{tabular}

Keterangan : Angka yang diikuti oleh huruf yang sama dalam kolom yang sama berarti tidak berbeda dengan uji Duncan pada taraf 5\%

Tabel 4 menunjukkan bahwa

perlakuan dosis pupuk kandang ayam, bobot basah terberat terdapat pada perlakuan A2 berbeda nyata dengan A1 dan A0, bobot basah pada perlakuan A1 berbeda nyata A0. Perlakuan frekuensi pemberian air, bobot basah tanaman bibit kelapa sawit terberat terdapat pada perlakuan R1 berbeda nyata dengan R2 dan R3. Bobot basah tanaman bibit kelapa sawit pada perlakuan $\mathrm{R} 2$ berbeda nyata dengan R3.

Hubungan antara dosis pupuk kandang ayam dengan bobot basah bibit tanaman kelapa sawit pada umur 12 MST disajikan pada Gambar 9.

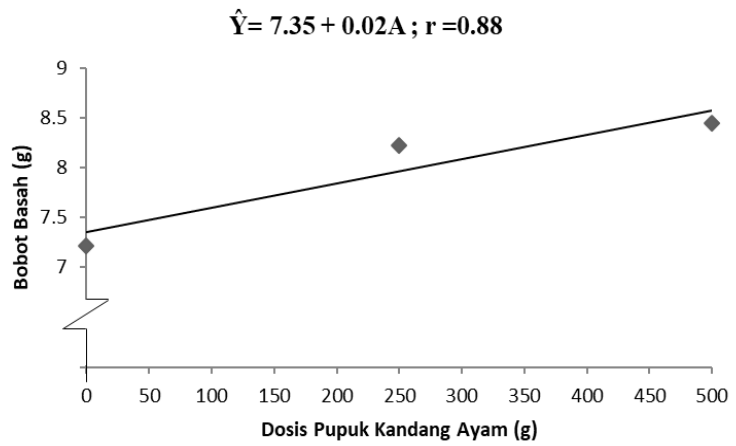

Gambar 9. Kurva Respon Pengaruh Dosis Pemberian Pupuk Kandang Ayam Terhadap Bobot Basah Bibit Tanaman Kelapa Sawit Pada Umur 12 MST.
Gambar 9 memperlihatkan bahwa semakin tinggi dosis pupuk kandang ayam maka bobot basah bibit tanaman kelapa sawit semakin meningkat mengikuti kurva regresi linear dengan persamaan $\hat{Y}=7.35+0.02$ A $; r=0.88$ yang berarti penigkatan pemberian pupuk kandang ayam $1 \mathrm{~g}$ akan meningkatkan bobot basah tanaman bibit kelapa sawit sebesar 0.02 g dengan keeratan hubungan $88 \%$.

Hubungan antarafrekuensi pemberian air dengan bobot basah tanaman bibit kelapa sawit pada umur 12 MST disajikan pada kurva respon (Gambar 10).

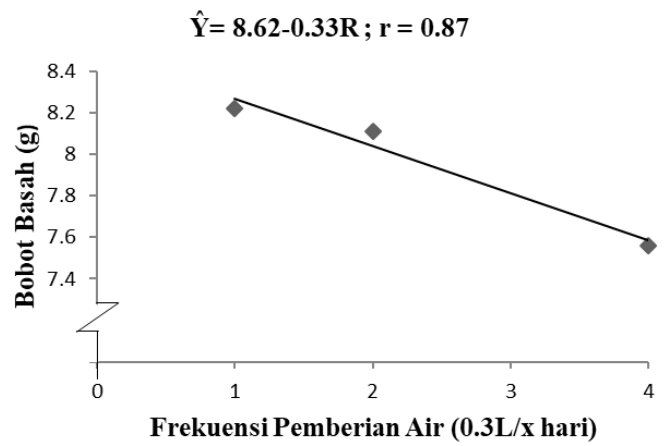

Gambar 10. Kurva Respon Pengaruh Pemberian Stress Air Terhadap Bobot Basah Tanaman Bibit Kelapa Sawit Pada Umur 12 MST 
Gambar 10 menunjukkan bahwa lama pemberian air, maka bobot basah tanaman kelapa sawit akan semakin menurun mengikuti kurva regresi linear dengan persamaan $\hat{\mathrm{Y}}=8.62-0.33 \mathrm{R} ; \mathrm{r}$ $=0.87$ yang berarti semakin lama frekuensi pemberian air 0.3 liter/polybag/2 hari akan menurunkan bobot basah bibit kelapa sawit sebesar $0.33 \mathrm{~g}$ dengan keeratan hubungan $87 \%$.

\section{SIMPULAN}

\section{Kesimpulan}

1. Perlakuan pupuk kandang ayam berpengaruh signifikan terhadap tinggi tanaman pada umur 10 dan 12 MST, panjang daun, lebar daun pada umur 12 MST.

2. Perlakuan stress air berpengaruh signifikan terhadap tinggi tanaman pada umur 8-12 MST, panjang daun, lebar daun pada umur 12 MST.

3. Kombinasi pupuk kandang ayam dan stress air berpengaruh tidak signifikan terhadap panjang daun, lebar daun, bobot basah pada umur 12 MST.

\section{Saran}

Untuk meningkatkan pertumbuhan bibit kelapa sawit disarankan menggunakan pupuk kandang ayam dengan dosis 50 $\% /$ polybag yang dikombinasikan dengan pemberian stress air dengan volume air 0,3 1/hari.

\section{DAFTAR PUSTAKA}

Arsyad.S.2010. Konservasi Tanah dan Air. Penerbit IPB.472.

Fauzi,dkk. 2012. Kelapa Sawit. Penebar Swadaya: Jakarta

Haryati.2003. Pengaruh Cekaman Air Terhadap Pertumbuhan dan Hasil Tanaman. Fakultas Pertanian Universitas Sumatera Utara:Medan.

Https:/www.google.com/amp/s/sinauter nak.com/pupuk-kandang

Https://id.wikipedia.org/wiki/Pupuk_ka ndang

Lingga dan Marsono,2006. Petunjuk Penggunaan Pupuk. Penebar Swadaya. Jakarta.

Lubis,dkk. 2011. Buku Pintar Kelapa Sawit. Jakarta: PT Agro Media Pustaka.

Mangonsoekarjo, S. G008.Manajement Agribisnis Kelapa Sawit. Gajah Mada Press.Yogyakarta.

Mukherjee, S. 2009. Health Effects off Palm Oil.J Hum Ecol 6 (3): 197-203.

Musnamar.2003. Pupuk Organik Cair dan Padat, Pembentukan dan Aplikasi. Penebar Swadaya. Jakarta.

Pahan,I. 2006. Panduan Lengkap Kelapa Sawit: Manajemen Harga Bisnis dari Hulu Hingga Hilir. Penebar Swadaya. Jakarta.

Pahan, I. 2008. Panduan Lengkap Kelapa Sawit. Jakarta: Penebar Swadaya

Pardamean, M. 2011. Sukses Membuka Kebun dan Pabrik Kelapa Sawit.Jakarta. Penebar Swadaya. 
Pardamean, Maruli. 2008. Panduan Lengkap Pengelolahan. Penerbit; Agro Media, Jakarta.

Risza,S. 1994. Kelapa Sawit, Upaya Peningkatan Produktivitas. Yogyakarta: Komisius.

Risza, S. 2000. Klasifikasi Kelapa Sawit.Kanisius. Jakarta

Song,dkk. 2011. Konsentrasi Klorofil Daun Sebagai Indikator Kekurangan Air Pada Tanaman.Jurnal Ilmiah Sains Volume 11 No.2. Hal 169-170.

Sunarko.2007. Petunjuk Praktis Budidaya dan Pengolahan
Kelapa Sawit. Jakarta (ID): Agromedia Pustaka. 70 Hal. Sunarko.2014. Budidaya Kelapa Sawit di Berbagai Jenis Lahan. Ag romedia.Jakarta.

Sulistio,B. 2010. Karya Dengan Bertani Kelapa Sawit. Yogyakarta: Penerbit Pustaka Baru. Press.146 Hal.

Syamsulbahri. 1996. Bercocok Tanam Tanaman Perkebunan Tahunan. Gadja Mada Press, Yogyakarta.

Vidanarko.2011. Buku Pintar Kelapa Sawit.Jakarta: Agromedia Pustaka. 